University of Nebraska - Lincoln

DigitalCommons@University of Nebraska - Lincoln

Faculty Publications, Department of Child, Youth, and Family Studies

2021

\title{
The Use of Family Engagement Principles by Childcare Providers From Various Childcare Settings: A Qualitative Study
}

John P. Rech

Kailey Snyder

Maggie Rasmussen

Dipti Dev

Danae Dinkel

Follow this and additional works at: https://digitalcommons.unl.edu/famconfacpub

Part of the Developmental Psychology Commons, Family, Life Course, and Society Commons, Other Psychology Commons, and the Other Sociology Commons

This Article is brought to you for free and open access by the Child, Youth, and Family Studies, Department of at DigitalCommons@University of Nebraska - Lincoln. It has been accepted for inclusion in Faculty Publications, Department of Child, Youth, and Family Studies by an authorized administrator of DigitalCommons@University of Nebraska - Lincoln. 


\title{
The Use of Family Engagement Principles by Childcare Providers From Various Childcare Settings: A Qualitative Study
}

\author{
John P. Rech, ${ }^{1}$ Kailey Snyder, ${ }^{2}$ Maggie Rasmussen, ${ }^{1}$ \\ Dipti Dev, ${ }^{3}$ and Danae Dinkel ${ }^{1}$ \\ 1 School of Health \& Kinesiology, University of Nebraska at Omaha, Omaha, \\ NE, USA \\ 2 School of Pharmacy and Health Professions, Creighton University, Omaha, \\ NE, USA \\ 3 College of Education and Human Sciences, University of Nebraska at Lincoln, \\ Lincoln, NE, USA \\ Correspondence - John P. Rech jprech@unomaha.edu School of Health \& Kinesiology, \\ University of Nebraska at Omaha, H\&K Building, 6001 Dodge Street, Omaha, NE \\ 68182, USA \\ ORCID \\ John P. Rech http://orcid.org/0000-0003-0031-2963
}

\begin{abstract}
Family engagement in childcare is important to ensure the optimal growth, development, and safety of children. Previous research has explored family engagement practices, but limited research is available on the application of theory to explain the uptake of family engagement principles. The purpose of this study was to explore the use and perceptions of the National Association of the Education for Young
\end{abstract}

Published in Child Care in Practice 2021

doi:10.1080/13575279.2021.1939656

Copyright (c) 2021 The Child Care in Practice Group; published by Routledge/Taylor\&Francis.

Used by permission.

Published 9 July 2021. 
Children's six principles of effective family engagement among childcare providers from various childcare settings following the Innovation-Decision Process of the Diffusion of Innovation Theory. A semi-structured interview with a card-sorting task was used to explore providers' knowledge, adoption, and perceived difficulty of implementation as well as their perceived outcomes, reasoning for use or non-use, and advice on use of the family engagement principles. Notable findings suggest variance in childcare providers' knowledge, adoption, and perceived difficulty of all six family engagement principles. Childcare providers mentioned various perceived outcomes and reasoning for use of principles, such as improved relationship with parents and enhanced child learning. Lack of time and perceived disinterest of parents were commonly reported difficulties for the use of family engagement principles. Future studies should expand upon the exploration of family engagement practices and comparison between different childcare settings and philosophies. Further efforts are needed to investigate effective integration and use of technology for communication.

Keywords: Parent involvement, daycare, early childhood development, Preschool, Toddler

\section{Introduction}

Early childhood ( $0-8$ years) is characterized by rapid, natural-occurring growth and development influenced greatly by the nurturing practices of caregivers (Lanigan et al., 2010). Although parents are considered to have the greatest influence on children's growth and development, 55\% (5.1 million) of families in the United States rely on some form of non-parental childcare on a near daily basis (Malik, 2019). Therefore, childcare providers also play a substantial role in the development of children's behaviors and must be willing to discuss with parents culturally appropriate and high-quality caregiving practices (Epstein, 2018).

A growing trend to achieve this is the intentional and multifaceted involvement of families in childcare, widely known as family engagement. The philosophy of family engagement is to help childcare providers and parents work in concordance with one another through the deliberate invitation to involve parents in multilevel decision making and provide diverse educational opportunities for children within the childcare setting, home, and community (Childcare Aware of America, n.d.; National Association for the Education of Young Children, n.d.). Importantly, family engagement practices should recognize that parent involvement in the childcare setting is 
a dynamic relationship that often fluctuates, should be culturally oriented, and intentionally empowering for both providers and families (Clifford \& Humphries, 2018). Research has found that childcare facilities with high levels of family engagement have improved quality of care as well as child and family health outcomes (Gelber \& Isen, 2013; Sivanand et al., 2017). Thus, due to the importance of family engagement in childcare, the implementation of family engagement principles is a substantial component of many Quality Rating and Improvement Systems (Childcare Aware of America, n.d.). One set of family engagement principles is by the National Association for the Education of Young Children (NAEYC). The NAEYC principles have a wide reach to providers and are comprehensive. For example, the six principles include shared child-level and program-level decision making, community engagement and wider advocacy, and two-way, reciprocal communication (see Table $\mathbf{1}$ for a more detailed outline of principles). Although studies exist on the exploration of family engagement in childcare, previous studies have not explored these six principles in-depth. Further, there is a lack of purely qualitative evidence supporting the adoption and implementation of specific family engagement principles in childcare (Barnes et al., 2016; Johnson et al., 2013).

In order to expand adoption of family engagement principles, the expansion of theoretical basis in the field is necessary. However, no known study has aimed to utilize theory to explain the uptake of particular family engagement principles by childcare providers (Barnes et al., 2016; Fan \& Yost, 2019; Garcia et al., 2018). One theory that could help to elucidate the uptake of family engagement principles is the Diffusion of Innovation (DOI) theory. DOI theory is used to determine the adoption of certain behaviors, practices, or policies, and the decision-making process used by members of a particular social system, which is identified as the Innovation-Decision Process (Rogers, 2003). This five-stage process helps to determine the extent to which innovations are either accepted or rejected by the community of interest (see Table 2). The Innovation-Decision Process of the DOI theory may help to delineate why and how childcare providers have used or not used family engagement principles in their practice to then alleviate any barriers that impede implementation. Therefore, the purpose of this study was to explore the use and perceptions of 
Table 1. National Association for the Education of Young Children - six principles of effective family engagement.

\begin{tabular}{|c|c|}
\hline Principle & Description \\
\hline $\begin{array}{l}\text { 1. Programs invite families to participate in } \\
\text { decision making and goal setting for their child. }\end{array}$ & $\begin{array}{l}\text { Programs invite families to actively take part in making decisions } \\
\text { concerning their children's education. Teachers and families } \\
\text { jointly set goals for children's education and learning both at } \\
\text { home and at school. }\end{array}$ \\
\hline $\begin{array}{l}\text { 2. Providers and programs engage families in } \\
\text { two-way communication. }\end{array}$ & $\begin{array}{l}\text { Strategies allow for both centers- and family-initiated } \\
\text { communication that is timely and continuous. Conversations } \\
\text { focus on a child's educational experience as well as the larger } \\
\text { program. Communication takes multiple forms and reflects } \\
\text { each family's language preference. }\end{array}$ \\
\hline $\begin{array}{l}\text { 3. Programs and teachers engage families in } \\
\text { ways that are truly reciprocal. }\end{array}$ & $\begin{array}{l}\text { Programs and families benefit from shared resources and } \\
\text { information. Programs invite families to share their unique } \\
\text { knowledge and skills and encourage active participation in the } \\
\text { life of the center. Teachers seek information about children's } \\
\text { lives, families, and communities and integrate this information } \\
\text { into their curriculum and teaching practices. }\end{array}$ \\
\hline $\begin{array}{l}\text { 4. Programs provide learning activities for the } \\
\text { home and in the community. }\end{array}$ & $\begin{array}{l}\text { Programs use learning activities at home and in the community } \\
\text { to enhance each child's early learning and encourage and } \\
\text { support families' efforts to create a learning environment } \\
\text { beyond the program. }\end{array}$ \\
\hline $\begin{array}{l}\text { 5. Programs invite families to participate in } \\
\text { program-level decisions and wider advocacy. } \\
\text { efforts }\end{array}$ & $\begin{array}{l}\text { Programs invite families to actively participate in making } \\
\text { decisions about the program itself. Programs also invite } \\
\text { families to advocate for early childhood education in the wider } \\
\text { community. }\end{array}$ \\
\hline $\begin{array}{l}\text { 6. Programs implement a comprehensive } \\
\text { program-level system of family engagement. }\end{array}$ & $\begin{array}{l}\text { Programs institutionalize family engagement policies and } \\
\text { practices and ensure that providers, directors, and other staff } \\
\text { receive the supports they need to fully engage families. }\end{array}$ \\
\hline
\end{tabular}

Adapted from National Association for the Education of Young Children (n.d.).

the NAEYC's six principles of effective family engagement among childcare providers from various childcare settings following the Innovation-Decision Process of the DOI Theory.

\section{Methods}

This study was part of a larger qualitative study exploring perceptions and use of best practices for family engagement on physical activity and healthy eating in childcare settings with providers and parents. The study was approved by a University affiliated Institutional Review Board (IRB) to ensure the ethical protection of participants. 
Table 2. Interview guide with definitions of theory stages.

\begin{tabular}{|c|c|c|}
\hline $\begin{array}{l}\text { Innovation-decision } \\
\text { process stage }\end{array}$ & Definition & Concepts addressed and example questions \\
\hline Knowledge & $\begin{array}{l}\text { In the knowledge stage, } \\
\text { a social system either } \\
\text { learns or knows about the } \\
\text { existence of an innovation } \\
\text { and to what extent have } \\
\text { they sought information } \\
\text { about the innovation. }\end{array}$ & $\begin{array}{l}\text { Knowledge was determined based on providers' responses } \\
\text { (Yes/No) to whether they have heard of the NAEYC and } \\
\text { the six principles of effective family engagement. } \\
\text { (1) Have you heard about the NAEYC and the six effective } \\
\text { principles regarding family engagement? }\end{array}$ \\
\hline Persuasion & $\begin{array}{l}\text { In the persuasion stage, } \\
\text { the social system will } \\
\text { show either a negative or } \\
\text { positive affect toward the } \\
\text { innovation. }\end{array}$ & $\begin{array}{l}\text { Persuasion was determined by the providers' responses } \\
\text { to questions asking their perceived impact of using a } \\
\text { principle. } \\
\text { (1) Have you seen any positive outcomes after initiating (this } \\
\text { principle)? Please explain. }\end{array}$ \\
\hline Decision & $\begin{array}{l}\text { In the decision stage, the } \\
\text { social system decides } \\
\text { whether to adopt or reject } \\
\text { the innovation. }\end{array}$ & $\begin{array}{l}\text { Decision was determined based on providers sorting the } \\
\text { cards as "uses", "does not use", and "unsure of use". } \\
\text { Here is a stack of cards that list effective principles regarding } \\
\text { family engagement practices. Could you put these cards } \\
\text { into } 3 \text { piles: } \\
\text { (1) One pile for principles that your center uses, } \\
\text { (2) One for principles that the center doesn't use, and } \\
\text { (3) One for principles that you haven't heard about or are } \\
\text { unsure about. }\end{array}$ \\
\hline Implementation & $\begin{array}{l}\text { In the implementation stage, } \\
\text { the social system puts the } \\
\text { innovation into practice. }\end{array}$ & $\begin{array}{l}\text { Implementation was determined by whether the providers } \\
\text { who used a principle thought it was easy or hard to use. } \\
\text { Providers were asked to sort the used principle cards into } \\
\text { "easy to do", "sometimes hard to do", and "really hard to } \\
\text { do." } \\
\text { Could you sort the cards you use into another } 3 \text { piles: } \\
\text { (1) Those that are easy to do, } \\
\text { (2) Those that you sometimes find hard to do, and } \\
\text { (3) One pile for really hard to do. }\end{array}$ \\
\hline Confirmation & $\begin{array}{l}\text { In the confirmation stage, } \\
\text { the social system looks for } \\
\text { support for their decision, } \\
\text { most often from those most } \\
\text { directly effecting them. }\end{array}$ & $\begin{array}{l}\text { Confirmation was determined based on providers' responses } \\
\text { to questions asking the reason they used a principle and } \\
\text { what advice they had on use. } \\
\text { (1) What are the main reasons for doing (this)? } \\
\text { (2) What advice would you give to providers who say that } \\
\text { they are not able to follow (this principle)? }\end{array}$ \\
\hline
\end{tabular}

Definitions adapted from Rogers (2003).

\section{Design}

This qualitative collective case study was guided by a directed content analysis approach (Creswell, 2007; Hsieh \& Shannon, 2005; Kohlbacher, 2006). A semi-structured interview style was used to allow the providers to naturally lead the conversation and the interviewer to 
prompt with questions for clarification when needed. Interview questions were constructed on the basis of the NAEYC's six principles of effective family engagement (Table 1 ) and guided by the InnovationDecision Process within the DOI Theory (Rogers, 2003; NAEYC, n.d.; see Table 2 for definitions related to DOI Theory). The application of existing theory was also used to limit the researchers' positionality and reflexivity in the collection and analysis of data, which is characteristic of a post-positivism methodological approach (Hyde, 2000). Interview questions were developed by the research team with expertise in promoting nutrition and physical activity in childcare settings, as well as conducting qualitative research. Interview questions were then pilot-tested through cognitive interviewing with a former childcare provider to ensure the design of questions and use of language were appropriate (Willis, 2004).

\section{Participants and setting}

A total of 11 childcare providers from 11 different family childcare homes (FCCH; $n=6$ ) and childcare centers (CCC; $n=5$ ) participated in this study. In this region, a family childcare home was defined as a facility that provides care to children within a private home by one or two individuals, whereas a childcare center provides care by multiple individuals (director and staff teachers) within a facility and children are divided into separate classrooms according to age (Nebraska Department of Health and Human Services, 2020). To be eligible for participation, providers were required to be a licensed lead teacher or owner at their respective childcare facility and cared for children aged o-5 years. The age range of children from o to 5 years was selected to exclude school aged children who may not receive daily, year around care from childcare providers. All childcare providers resided within a metropolitan area in the Midwestern United States.

Participants were recruited through participation in the Nebraska Nutrition and Physical Activity Self Assessment for Child Care (Go NAP SACC) program, the Nebraska Department of Health and Human Services' Roster of Licensed Child Care and Preschool Programs, and childcare organization Facebook pages. Childcare providers were emailed a description of the study with a voluntary eligibility survey attached in the e-mail. If deemed eligible, providers were contacted 
via their preferred mode of contact. A narrative consent was provided and/or read aloud to the providers and if they provided consent, a date and time were scheduled for the interview to take place in person at the provider's facility. The selection of participants was determined through maximum variation purposive sampling in order to have an equal representation of $\mathrm{CCC}$ and $\mathrm{FCCH}$ providers ( $\mathrm{Pa}-$ linkas et al., 2015).

\section{Data collection}

All interviews were conducted by one female, undergraduate student who was trained to conduct qualitative semi-structured interviews by a highly experienced qualitative researcher. The undergraduate student also followed general qualitative procedures for conducting interviews, provided by Jacob and Furgerson (2012). The senior researcher oversaw all data collection, including listening to practice interviews until she felt the student was ready to collect data. Additionally, she listened and provided feedback on the first few interviews until she was confident in the student researcher's abilities. The interviewer had no prior relationships with the participants of this study. Interviews were conducted one time with each participating childcare provider within their childcare facility between July 2019 and January 2020. The interviewer followed a detailed script and interview guide. Interviews were audio recorded and lasted approximately one hour. Participants completed a demographic survey via an online survey tool. Demographics included gender, level of education, and race/ethnicity.

The Innovation-Decision Process within the DOI Theory was used to assess childcare providers use of the six principles of effective family engagement by utilizing a semi-structured interview with a card-sorting task (Dev et al., 2014; Rugg \& McGeorge, 1997). The use of Innovation-Decision Process has been used previously in other research to assess the adherence of best practice guidelines, such as for doctors within clinical practice and physical therapists for routine lower back pain treatment (Hader et al., 2007; Harting et al., 2009). These studies demonstrated that the DOI theory can add value to implementation studies oriented in guideline or principle adoption and adherence. 
Card sorting, as a methodology, was chosen as this approach has been recommended for helping practitioners understand the users' comprehension and may provide insight into how users would group content to perform common tasks, which in this particular case was family engagement practices (Whaley \& Longoria, 2009). The card sorting task consisted of having each of the six family engagement principles written on a separate card with a short description, which was advantageous for the participants to hear and see the principles since some childcare providers may have been unfamiliar with the NAEYC's principles. All cards were handed to the provider at one time from the interviewer. To determine their decision on use, the provider sorted the cards as "uses" meaning yes, the providers used this principle within their facility, "does not use" meaning no, they did not use this principle, or "unsure about use" meaning they were unsure what the principle meant or were unsure of use. Next, the interviewer asked the participant to sort the "uses" pile into "easy to do", "sometimes hard to do", or "really hard to do", to determine the implementation of principles. Once sorted the interviewer reviewed each card and then asked additional questions based on the DOI Theory to determine why they sorted the cards the way they did. The interview guide can be found in Table 2 .

\section{Data management and analysis}

Childcare provider responses were transcribed verbatim and then uploaded into QSR NVIVO 12 (Version 12.6.0). Using an investigator triangulation approach, data were read over and reviewed multiple times by two researchers to ensure validity of data. Following a post-positivism methodological approach, the two researchers then deductively developed the coding scheme with a codebook to provide definitions of codes following the five stages of the Innovation-Decision Process of the DOI Theory (Sim \& Sharp, 1998). Underneath each stage, researchers inductively developed codes. One researcher then proceeded with the initial coding of participants' responses following the agreed upon coding scheme. The other researcher reviewed all coding, and then the two researchers met to discuss any discrepancies until consensus was reached. Peer debriefing by a third researcher was used to review the coding scheme and the coded data to ensure the validity and reliability of the data (Creswell \& Miller, 2000). All three researchers then 
Table 3. Childcare providers' knowledge and decision of the NAEYC's six principles of effective family engagement.

Number of childcare providers (\%)

\begin{tabular}{lccc}
\hline Knowledge & Heard of & Maybe & Not heard of \\
NAEYC Family Engagement Principles & $2(18.2)$ & $3(27.3)$ & $6(54.5)$ \\
Decision & Used & Did not use & Unsure of use \\
Principle 1 & $9(81.8)$ & $2(18.2)$ & 0 \\
Principle 2 & $10(90.9)$ & $1(9.1)$ & 0 \\
Principle 3 & $11(100)$ & 0 & 0 \\
Principle 4 & $8(72.7)$ & $1(9.1)$ & $2(18.2)$ \\
Principle 5 & $4(36.3)$ & $4(36.3)$ & $3(27.3)$ \\
Principle 6 & $5(45.5)$ & $1(9.1)$ & $5(45.5)$ \\
\hline
\end{tabular}

met to discuss any discrepancies until consensus was reached and data were deemed valid and trustworthy (Korstjens \& Moser, 2018). An audit trail with thick description was kept of the research steps to ensure the dependability, confirmability, and transferability of the qualitative research protocol used in this study (Korstjens \& Moser, 2018; Sim \& Sharp, 1998).

\section{Results}

All participants were female, of which a majority had at least some college experience. Seven childcare providers identified as White and others identified as being either Black $(n=2)$ or Hispanic $(n=2)$. Childcare providers had an average age of $45.5 \pm 13.2$ years with 20.8 \pm 12.5 years of experience. Table 3 displays the participating childcare providers' knowledge of NAEYC's six principles of effective family engagement, and decision on use (i.e. used, did not use, or unsure of use) for each principle. The six providers who stated they had not heard of the NAEYC's family engagement principles were all $\mathrm{FCCH}$ providers. Additionally, a greater number of providers reported using principles 1-3, compared to principles 4-6. More providers also reported being unsure of use for principles 4-6, than principles 1-3. The major themes based on the Innovation-Decision Process, including those for persuasion, implementation, and confirmation are discussed by principle in more detail below. 


\section{Principle 1: decision making and goal setting for child}

\section{Persuasion}

The perceived outcomes of including families in decision making and goal setting for the child included learning outcomes for both child and parent and/or provider. In reference to child learning outcomes, providers discussed how the focus was often on eating habits and potty training. For example, one FCCH provider said,

If the child is now eating a certain food and they weren't before we want to build on that and try to incorporate that at home as well so they [child] continue to see that is a good thing to do.

Providers also discussed parent and/or provider learning outcomes, such as acknowledging and communicating that the child is learning, as one CCC provider said, "A lot of times parents have information that we don't have and they are able to tell us what it is they want us to work on."

\section{Implementation}

Of the nine providers who said they used this principle, seven reported it was easy to use and two providers reported this principle was hard to use. Decision making and goal setting for children were conducted through formal parent-provider conferences and informal open communication, via e-mail or face-to-face meetings during pick up and drop off times. A CCC provider who described this principle as hard to use stated, "It is hard to do because you want them to be involved but you also want them to respect the boundaries, we can't do something different for every single child."

\section{Confirmation}

Reasons for using this principle included to benefit children's learning and to involve parents more in their child's learning. For example, one CCC provider mentioned, "So that we can help the whole child. If we don't know what they need help with then we can't put our resources in the right direction." When providing advice on how to use this principle numerous providers stated they used conferences and 
utilized technology for communication including texting, e-mailing, and apps such as ClassDojo and Facebook Messenger. In reference to how conferences were used, one CCC provider stated, "Just start off small, do it maybe once at the beginning of the year and once in the middle of the year." The main reason why childcare providers did not use this principle was because they did not want parents to tell them how to do their job. For example, a FCCH provider said, "I wouldn't want families to tell me what to do or should do, I prefer to make that decision." One provider also mentioned it was because they let the child make more of those individual decisions for themselves.

\section{Principle 2: two-way communication}

\section{Persuasion}

The perceived outcomes of two-way communication among providers were to show parents that children are happy, to improve how child behavior is reinforced, and to better relationships with parents. A CCC provider mentioned her reason for using this principle was, "To help us understand a child's behavior and why it seems out of the blue that they are behaving this way but it can also change our approach to the child and how we handle the situation." As for bettering relationships with parents, a FCCH provider stated, "The more you can talk with them (parents), the more they open up, the more they are comfortable with having their child here and just feeling at home when walking in."

\section{Implementation}

Of the ten providers who said they used this principle, six providers reported it was easy to use, whereas four reported it was hard. Providers applied two-way communication through a variety of ways including face-to-face interactions, texting, e-mailing, parent-provider conferences, and apps. Barriers were evident for all providers, whether they stated this principle was easy or hard to use, but all barriers mentioned by providers were in reference to parents. For instance, providers reported that parents "have their guard up", “just don't want to talk", "sometimes don't want to listen", and/or "did not have enough time to talk." 


\section{Confirmation}

Reasons for using this principle included improving the quality of communication between providers and parents and it being common sense. For example, one CCC provider mentioned, "So we know what they want and what we can do and they know what we want and what we hope they are going to do." The advice given by providers included: "Try to find something to talk to a parent about every day" and "work on getting to know, not only the child, but also the parents."

\section{Principle 3: truly reciprocal}

\section{Persuasion}

The perceived outcomes for engaging families in ways that are truly reciprocal included to please and accommodate parents and to meet the needs of the child. For example, a FCCH provider mentioned pleasing and accommodating parents by stating, "I have had lots of parents that were very open and receptive to anything I have encouraged them to do or try." As for meeting the needs of the child, one CCC provider said, "...the child is getting what they deserve and the needs of the child are being met at the highest level possible."

\section{Implementation}

Out of the eleven providers, five providers reported this principle was easy to do, whereas, six reported this principle was hard. Providers engaged families in ways that were truly reciprocal through sharing caregiving and activity ideas and using a variety of communication channels. The reasons for why this principle was hard to use was because of the difficulty in getting parents to talk or reciprocate with providers, lack of time for both parents and providers, and the difficulty of being the only childcare provider (specifically for FCCH providers). One CCC provider stated, "Sometimes it is hard because they are like 'nope we don't need anything' and so we don't know what they truly need, to make it valuable for them as a family."

\section{Confirmation}

Reasons for using the principle included sharing knowledge with parents, making sure the needs of children were being met, and that parents and providers were on the same page. One CCC provider 
mentioned, "If you are open and honest and a parent is open and honest then I feel like you know you are going to best effectively serve that child." Providers gave advice by mentioning the use of a handbook to educate parents, keeping all channels of communication open, and building rapport to improve the reciprocation between parents and providers. One FCCH provider stated, "Maybe if the parents were educated more about how important it is [to reciprocate], if they understood why the provider likes to know. The parents need to be a little more educated, like a handbook." A CCC provider mentioned, "Start small with little, small steps until they become more comfortable with you and then start working up to having a conversation."

\section{Principle 4: learning activities for the home and in the community}

\section{Persuasion}

The perceived outcomes for providing learning activities for the home and in the community included to benefit the child and to involve parents in the child's learning. For example, a FCCH provider said, "I have seen kids get a little more excited about doing things because their parents are helping them." One CCC provider said, "they [children] really enjoy being able to take toys that we do have here at the center, home, and then bring them back."

\section{Implementation}

Out of the eight providers who used this principle, seven of them reported it was easy to use and only one provider reported it was hard to use. Activities that providers mentioned they offered families to take home included books, cooking recipes, and/or learning- oriented worksheets. For example, one FCCH provider mentioned, "I send home resources that the kids have worked on with me so the kids can come home and explain to their parents and be excited about it." Learning activities within the community that providers mentioned they have accessed included the library, pumpkin patch, community gardens, and public parks that were within close proximity to the childcare facility. Some providers stated they did not have any barriers when implementing this principle, while other providers' perceived barriers included parents not wanting to participate in activities that were sent home and a lack of time for both parents and providers. For example, a 
FCCH provider said, "Some parents don't have the time...even though you give them many ideas or examples."

\section{Confirmation}

Reasons for using this principle included involving the parents in the child's learning and getting the children interested in their community. For example, one FCCH provider mentioned, "It helps parents, as far as activities sent home, it just helps them know how kids learn best, it's not like through flash cards and drilling, it is activities." Providers gave an assortment of advice for using this principle. A FCCH provider suggested, "Be creative, but you have to make some things simple because parents are very busy." A CCC provider suggested, "Look into something that the parents are interested in." The one provider (CCC) who stated they didn't use this principle said, "We don't have resources that we pass out, and the purpose of our education here is the classroom isn't something they can take home."

\section{Principle 5: program-level decision making and wider advocacy}

\section{Persuasion}

The perceived outcomes for involving families in program-level decision making and wider advocacy included gaining support from parents and for providing encouragement to staff. For example, one CCC provider said, "We've invited parents and we have actually partnered up with some of the businesses that they are at." Another CCC provider said, "I think it is nice to have those agents [parent advisory board members] who can go to bat to say, look here this is what your staff is doing well, keep doing this!”

\section{Implementation}

Of the four providers who used this principle, three reported this was easy and one provider reported it was hard. Those three providers who considered this to be easy mentioned, they engaged families in program-level decision making through parent advisory boards or committees. The one provider who considered this to be hard mentioned, "I send out a survey about once a year to get their feedback on how things are going." The perceived barriers when using this principle included parents not showing up to council meetings and only a few parents filling out the survey. 


\section{Confirmation}

Reasons for using this principle included to increase parent involvement and support as well as this being something they have just done for a long time. For example, a FCCH provider mentioned, "So parents are on board with what you are doing and support you." The advice given by one CCC provider included, "Just say 'hey you know if we were to start a parent advisory committee is that something you would be interested in giving input to." The providers who stated they do not use this principle said, "I feel like it is more of a center based thing" and "I feel like there would be too many opinions and some parents get too overbearing."

\section{Principle 6: comprehensive program-level system of family engagement}

\section{Persuasion}

The perceived outcomes of implementing a comprehensive programlevel system of family engagement included to improve relationships with parents and to improve child behavior. For example, a FCCH provider said, "It is important because if you don't communicate then you don't have a relationship [with parents]." Another FCCH provider mentioned to improve child behavior by stating, "Because you are reinforcing, you know you are going to have to discipline one child so we need to pass on what they did, what the discipline was, you need to reassure the parent."

\section{Implementation}

Of the five providers who used this principle, only one provider reported it was easy and the rest reported it was hard. Providers implemented this principle by having a family engagement policy, sending a weekly email or monthly newsletter to all parents, or simply using open communication. Providers mentioned a lack of time for both parents and providers, lack of communication from parents, and not having enough staff as perceived barriers. One FCCH provider mentioned, "It is difficult just to make sure that everybody is on the same page as far as communicating things that need to be communicated ... the end of the day ... is a big rush." 


\section{Confirmation}

The reason for using this principle included to keep communication open between providers and parents. A CCC provider mentioned, "It is important to keep communication so you are all on the same page of what we are doing. I think that is why it is important because if you don't communicate then you don't have a relationship." Advice given by providers who said they used this principle included having a handbook, hiring high quality staff, and designating a place to speak privately with parents. For example, one FCCH provider said, "Have a spot where you could step away and speak privately. Like 'could you come upstairs for a minute with me or step down on the porch.” The reason why the one provider said they did not use this principle was due to a lack of other staff present in the childcare facility.

\section{Discussion}

The purpose of this qualitative study was to explore the use and perceptions of the NAEYC's six principles of effective family engagement among childcare providers from various childcare settings following the Innovation-Decision Process of the DOI Theory. Family engagement is necessary in order to involve families in culturally appropriate and health-conscious strategies that are developmentally and educationally focused for children within the childcare facility, children's home, and community (Clifford \& Humphries, 2018; Epstein, 2018; NAEYC, n.d.). The application of DOI provided several key insights to better understand the uptake of family engagement principles and how to alleviate barriers that impede the long-term implementation of comprehensive family engagement (Pollard et al., 2001).

\section{Adoption of NAEYC's principles based on the Innovation-Decision Process}

The childcare providers in this study proved to vary on where they reside in the Innovation- Decision Process, on a principle by principle basis, as well as their implementation of specific family engagement practices. Although only two childcare providers reported having knowledge of the NAEYC's family engagement principles, all childcare 
providers stated they had used at least a few principles and had success. Based on the findings of this study, it seems as if a majority of childcare providers are persuaded to implement basic family engagement principles (principles 1-3) through the experience of positive outcomes, such as establishing eating habits and potty training at the child level and finding a common ground to communicate at the parent level. This result is consistent with previous research that found providers were motivated to engage parents because they felt responsible for instilling positive health outcomes in children and the importance of engaging families (Swindle et al., 2018). However, in the present study, some providers voiced concerns on parents' lack of interest in communication or failure to reciprocate exchanges of information with providers on child or family matters, a difficulty to get parents more involved in the child's learning and development, as well as a lack of time being a major restraint for both parents and providers (Baker et al., 2016; Lamb-Parker et al., 2001).

As for the latter half of the NAEYC's family engagement principles (principles 4-6), the majority of providers reported a lack of use or were unsure of use, particularly for getting involved in the community, engaging families in program-level decision making and wider advocacy, and having comprehensive family engagement within their program. This is similar to findings of other studies that such practices have been challenging to achieve within childcare (Baker et al., 2016; Dev et al., 2017; Garcia et al., 2018; Lamb-Parker et al., 2001; Lyn et al., 2014). Importantly, any areas of uncertainty on how to implement principles prevents the confirmation of comprehensive efforts. Thus, in order for childcare facilities to achieve a comprehensive approach to family engagement, providers should start out small and slowly build their way up to the eventual achievement of all principles, as suggested by multiple providers in this study. An easily implementable first step to more comprehensive family engagement may be to include parents in some aspects of decision making for the childcare facility. By opening up some decision making to parents and incorporating more of their ideas or activities into childcare this may further open up the possibility for more parent and provider collaboration by also co-planning events and/or meals offered through childcare (Douglass, 2011). One way in which numerous CCCs were successfully 
implementing comprehensive practices in our study was through the use of a parent advisory board; however, this may not be an applicable practice for FCCHs given there are a fewer number of parents, and providers typically already have close relationships with families. FCCH providers may desire to have more informal conversations with parents individually and/or develop family nights where providers could meet with all families to gather input.

\section{Using technology to increase communications}

Providers may want to consider simpler ways in which they can more comprehensively involve parents and open up dialogue in a more timeefficient manner, particularly through the use of technology. A family engagement practice that was often mentioned by providers were parent-provider conferences, but providers stated they frequently struggled to get parents to attend, which is similar to findings of other studies (Dev et al., 2017; Lyn et al., 2014). Providers should consider using a variety of communication channels (e.g. e-mail, text messaging, social media, or messaging apps) when connecting with parents to discuss child- and program-level outcomes. For instance, providers may ask parents what creative and engaging activities their children enjoy doing with family or friends to then implement within the childcare facility. Another solution to alleviate barriers of communication is to utilize secure platforms of social media or apps for direct or group messaging, such as ClassDojo, as mentioned by one participant. In order to ensure the sharing of children's information and/or photos is appropriately protected, it is also important for childcare providers to identify platforms and software that are secure (Fan \& Yost, 2019). Additionally, providers could also take advantage of technology by sending out information and reminders for upcoming events or learning opportunities within their childcare program and the community (Barnes et al., 2016; Reedy \& McGrath; 2010; Snell et al., 2020).

Further, to more elaborately include families in program-level and individual child decision making, childcare providers should provide continual updates on children's learning and development to parents, which can be efficiently achieved through the use of technology (Barnes et al., 2016; Fan \& Yost, 2019; Swindle et al., 2018). Future studies on engaging parents should explore the implementation and 
effectiveness of using different types of platforms to contact parents. Another possible solution to gain parents' perspectives is to give parents the option of anonymously completing feedback surveys, which can be used for effective program evaluation as well as so parents feel that their opinions are being heard and considered (Edwards \& Redfern, 2017). Such surveys can also be sent out through a variety of channels such as social media, e-mail, or hard copy.

\section{Community engagement and wider advocacy}

Several childcare providers reported a difficulty or lack of connection with community organizations. Libraries, pumpkin patches, community gardens, and public parks were community organizations or resources childcare providers had mentioned in this study; however, additional organizations may include museums, healthcare centers, higher education institutions, and local businesses. Additionally, these community organizations may help to respond and achieve family needs and interests related to child development by providing structured programs, ideas and options to parents they may not have been previously aware of (Evans, 2013). Given this is an understudied topic within childcare, future studies should focus on childcare providers' existing engagement with community organizations as well as how to improve these relationships to make them mutually beneficial for all parties involved.

\section{Policies and continuing education}

Furthermore, providers should develop policies specific to family engagement in order to improve adherence to family engagement principles. Policies specific to family engagement would also help to resolve uncertainty of whether or not the childcare program uses certain principles (Dev et al., 2017; Garcia et al., 2018). Providers may want to consider developing handbooks that highlight effective strategies to inform both workers and families on comprehensive policies and practices, such as program-level decision making, wider advocacy for early childhood education, and community involvement. Handbooks could alleviate some uncertainty of if and how childcare programs use family engagement (Reedy \& McGrath; 2010). 
Further, state government departments that regulate childcare should endorse family engagement practices for all types of childcare, ensure providers receive continuous professional development on these principles, and integrate them into licensing standards (Lyn et al., 2014; Pollard et al., 2001). Preparation on the use of family engagement practices within post-secondary education or pre-professional trainings may also help to educate pre-service childcare providers on how to alleviate potential barriers and establish a comprehensive family engagement program (Evans, 2013; Miller et al., 2013). Lastly, in order for childcare programs to continue to adopt family engagement principles, associations like the NAEYC that promote family engagement, could provide explicit examples of how principles could be enacted according to the type of childcare facility (Sivahand et al., 2017). For instance, due to lower enrollment numbers at FCCHs, providers may have more liberty in interacting with parents and therefore some practices, such as parent-teacher conferences, may not be relevant. However, CCCs may be more apt to implement a comprehensive family engagement program due to the responsibilities dispersed among multiple providers, whereas in a $\mathrm{FCCH}$ all responsibilities are given to one or possibly two providers. Therefore, by providing best practices specific to program type, childcare providers may better understand how to overcome barriers to implementation and be persuaded to adopt family engagement principles.

\section{Limitations}

The generalizability of findings in this study should be done so with caution due to the small sample size garnered from within one Midwestern, metropolitan city in the United States. Although this is the first study to utilize theory to explore the use of family engagement principles across various childcare settings, a comparison of the actual practices and perceived outcomes of these principles based on childcare type was not achievable due to the small sample size. Future studies should look to expand the sample size in order to do so. Additionally, findings of this study are reflective of a larger qualitative study in which childcare providers completed a semi-structured interview in regard to their use of physical activity and healthy eating practices. 
Therefore, childcare providers may have responded solely according to those health practices, rather than to family engagement practices as a whole. Another limitation is that although the DOI theory is intended to delineate the adoption and use of evidence-based practices, it may not fully encapsulate uptake of family engagement practices by childcare providers. Further, despite applying multiple validation and reliability strategies for qualitative research, social desirability and recall bias may have swayed participants' responses to interview questions. Lastly, personal biases and previous knowledge of the researchers may have influenced the interpretation of these findings.

\section{Conclusion}

While the NAEYC has wide reach, there was a clear distinction in implementing the principles. The majority of providers reported engaging families through various personalized communication channels, but also reported limited implementation of principles that involved families in shared decision-making, wider advocacy, and community partnership. Based on the Innovation-Decision Process regarding persuasion, the first step for NAEYC and policy makers is to enlighten providers about the importance of implementing the principles for shared decision-making with families. Further, childcare providers, as reported in this study, may feel vulnerable about being told what to do in their childcare practice, so additional training and tools are needed on how to facilitate collaborative decision making between providers and families. The use of technology through secure platforms or software, social media, or emerging applications and texting should be further explored in engaging families to implement the principles since providers consistently reported barriers inherent to parents regarding lack of time and interest.

Acknowledgments The authors would like to thank the childcare providers who took time to participate in this study.

Disclosure No potential conflict of interest was reported by the authors.

Funding This study was funded by the Fund for Undergraduate Scholarly Excellence from the University of Nebraska at Omaha. 


\section{Contributors}

John P. Rech is a Ph.D. student and research assistant in the School of Health and Kinesiology at the University of Nebraska at Omaha. His work focuses on the promotion and development of physical activity and other health-related behaviors of children, particularly of early childhood and primary school age, and their caregivers.

Kailey Snyder Ph.D. is an assistant professor in the School of Pharmacy and Health Professions at Creighton University. Her work focuses on maternal/child health with an emphasis on physical activity during the prenatal/postpartum period.

Maggie Rasmussen holds a B.S. in public health and is currently a Master's student in the same discipline in the School of Health \& Kinesiology at the University of Nebraska at Omaha, where she also serves as a graduate assistant.

Dipti Dev Ph.D. is an associate professor in the College of Education and Human Sciences at the University of Nebraska at Lincoln. Her research focuses on the area of child development and early childhood education.

Danae Dinkel Ph.D. is an associate professor in the School of Health and Kinesiology at the University of Nebraska at Omaha. Her research focuses on the promotion of physical activity and other health behaviors related to the prevention of childhood obesity, particularly during early childhood.

\section{References}

Baker, T. L., Wise, J., Kelley, G., \& Skiba, R. J. (2016). Identifying barriers: Creating solutions to improve family engagement. School Community Journal, 26(2), 161-184. https://eric.ed.gov/?id=EJ1124003.

Barnes, J. K., Guin, A., Allen, K., \& Jolly, C. (2016). Engaging parents in early childhood education: Perspectives of childcare providers. Family and Consumer Sciences Research Journal, 44(4), 36o-374. https://doi.org/10.1111/fcsr.12164

Childcare Aware of America. (n.d.). Family engagement in QRIS. https://www.childcareaware.org/child-care-resource-and-referral/ consumer-education-engagement/family-engagement-in-qris/

Clifford, A. P., \& Humphries, M. L. (2018). Parent involvement in US early childhood education: Benefits, limitations, and reconceptualizations. In M. Fleer \& B. van Oers (eds.) International handbook of early childhood education (pp. 767-786). Springer.

Creswell, J. W. (2007). Five qualitative approaches to inquiry. Qualitative Inquiry and Research Design: Choosing Among Five Approaches, 2, 53-80.

Creswell, J. W., \& Miller, D. L. (2000). Determining validity in qualitative inquiry. Theory into Practice, 39(3), 124-130. https://doi.org/10.1207/ s15430421tip3903 2 
Dev, D. A., Byrd-Williams, C., Ramsay, S., McBride, B., Srivastava, D., Murriel, A., \& Adachi- Mejia, A. M. (2017). Engaging parents to promote children's nutrition and health: providers' barriers and strategies in head start and child care centers. American Journal of Health Promotion, 31(2), 153-162. https://doi. org/10.1177/0890117116685426

Dev, D. A., Speirs, K. E., McBride, B. A., Donovan, S. M., \& Chapman-Novakofski, K. (2014). Head Start and child care providers' motivators, barriers and facilitators to practicing family-style meal service. Early Childhood Research Quarterly, 29(4), 649-659. https://doi.org/10.1016/j.ecresq.2014.07.004

Douglass, A. (2011). Improving family engagement: The organizational context and its influence on partnering with parents in formal child care settings. Early Childhood Research \& Practice, 13 (2), n2. https://eric.ed.gov/?id=EJ956369

Edwards, V., \& Redfern, A. (2017). At home in school (1988): Parent participation in primary education. Routledge.

Epstein, J. L. (2018). School, family, and community partnerships: Preparing educators and improving schools. Routledge.

Evans, M. P. (2013). Educating preservice teachers for family, school, and community engagement. Teaching Education, 24(2), 123-133. https://doi.org/1 0.1080/10476210.2013.786897

Fan, S., \& Yost, H. (2019). Keeping connected: Exploring the potential of social media as a new avenue for communication and collaboration in early childhood education. International Journal of Early Years Education, 27(2), 132-142. https://doi.org/10.1080/09669760.2018.1454301

Garcia, A. S., Dev, D. A., \& Stage, V. C. (2018). Predictors of parent engagement based on child care providers' perspectives. Journal of Nutrition Education and Behavior, 50(9), 905-912. https://doi.org/10.1016/j.jneb.2018.06.009

Gelber, A., \& Isen, A. (2013). Children's schooling and parents' behavior: Evidence from the Head Start Impact Study. Journal of Public Economics, 101, 25-38. https://doi.org/10.1016/j.jpubeco.2013.02.005

Hader, J. M., White, R., Lewis, S., Foreman, J. L., McDonald, P. W., \& Thompson, L. G. (2007). Doctors' views of clinical practice guidelines: A qualitative exploration using innovation theory. Journal of Evaluation in Clinical Practice, 13(4), 601-6o6. https://doi.org/10.1111/j.1365-2753.2007.00856.x

Harting, J., Rutten, G. M., Rutten, S. T., \& Kremers, S. P. (2009). A qualitative application of the diffusion of innovations theory to examine determinants of guideline adherence among physical therapists. Physical Therapy, 89(3), 221232. https://doi.org/10.2522/ptj.20080185

Hsieh, H. F., \& Shannon, S. E. (2005). Three approaches to qualitative content analysis. Qualitative Health Research, 15(9), 1277-1288. https://doi. org/10.1177/1049732305276687

Hyde, K. F. (2000). Recognising deductive processes in qualitative research. Qualitative Market Research: An International Journal. 3(2), 82-90. https://doi. org/10.1108/13522750010322089 
Jacob, S. A., \& Furgerson, S. P. (2012). Writing interview protocols and conducting interviews: Tips for students new to the field of qualitative research. Qualitative Report, 17(42), 1-10. https://doi.org/10.46743/2160-3715/2012.1718

Johnson, S. L., Ramsay, S., Shultz, J. A., Branen, L. J., \& Fletcher, J. W. (2013). Creating potential for common ground and communication between early childhood program staff and parents about young children's eating. Journal of Nutrition Education and Behavior, 45(6), 558-570. https://doi.org/10.1016/j. jneb.2013.02.009

Kohlbacher, F. (2006). The use of qualitative content analysis in case study research. Forum Qualitative Sozialforschung/Forum: Qualitative Social Research, 7(1), 1-30. http://dx.doi.org/10.17169/fqs-7.1.75

Korstjens, I., \& Moser, A. (2018). Series: Practical guidance to qualitative research. Part 4: Trustworthiness and publishing. European Journal of General Practice, 24(1), 120-124. https://doi.org/10.1080/13814788.2017.1375092

Lamb-Parker, F., Piotrkowski, C. S., Baker, A. J., Kessler-Sklar, S., Clark, B., \& Peay, L. (2001). Understanding barriers to parent involvement in Head Start: A research-community partnership. Early Childhood Research Quarterly, 16(1), 35-51. https://doi.org/10.1016/So885-2006(01)00084-9

Lanigan, J., Barber, S., \& Singhal, A. (2010). Prevention of obesity in preschool children. Proceedings of the Nutrition Society, 69(2), 204-210. https://doi. org/10.1017/So029665110000029

Lyn, R., Evers, S., Davis, J., Maalouf, J., \& Griffin, M. (2014). Barriers and supports to implementing a nutrition and physical activity intervention in child care: Directors' perspectives. Journal of Nutrition Education and Behavior, 46(3), 171-180. https://doi.org/10.1016/j.jneb.2013.11.003

Malik, R. (2019). Working families spending big money on childcare. https://www.americanprogress.org/issues/early-childhood/ reports/2019/06/20/471141/working-families-spending-big-money-child-care/

Miller, G. E., Lines, C., Sullivan, E., \& Hermanutz, K. (2013). Preparing educators to partner with families. Teaching Education, 24(2), 150-163. https://doi.org/1 $0.1080 / 10476210.2013 .786889$

National Association for the Education of Young Children. (n.d.). Principles for effective family engagement. https://www.naeyc.org/resources/topics/ family-engagement/principles

Nebraska Department of Health and Human Services. (2020). Childcare licensing. http://dhhs.ne.gov/licensure/Pages/Child-Care-Licensing.aspx

Palinkas, L. A., Horwitz, S. M., Green, C. A., Wisdom, J. P., Duan, N., \& Hoagwood, K. (2015). Purposeful sampling for qualitative data collection and analysis in mixed method implementation research. Administration and Policy in Mental Health and Mental Health Services Research, 42(5), 533-544. https://doi. org/10.1007/s10488-013-0528-y

Pollard, C., Lewis, J., \& Miller, M. (2001). Start right-eat right award scheme: Implementing food and nutrition policy in child care centers. Health Education \& Behavior, 28(3), 320-330. https://doi.org/10.1177/109019810102800306 
Reedy, C. K., \& McGrath, W. H. (2010). Can you hear me now? Staff-parent communication in child care centres. Early Child Development and Care, 180(3), 347-357. https://doi.org/10.1080/03004430801908418

Rogers, E. (2003). Diffusion of innovations. Free Press.

Rugg, G., \& McGeorge, P. (1997). The sorting techniques: A tutorial paper on card sorts, picture sorts and item sorts. Expert Systems, 14(2), 80-93. https://doi. org/10.1111/1468-0394.00045

Sim, J., \& Sharp, K. (1998). A critical appraisal of the role of triangulation in nursing research. International Journal of Nursing Studies, 35(1-2), 23-31. https://doi.org/10.1016/S0020-7489(98)00014-5

Sivanand, B., Herman, A., Teutsch, C., \& Teutsch, S. (2017). Building health literacy and family engagement in head start communities: A case study. https://nam.edu/wp-content/uploads/2017/04/Building-Health-Literacy-andFamily-Engagement-in-Head-Start-Communities.pdf

Snell, E. K., Hindman, A. H., \& Wasik, B. A. (2020). Exploring the use of texting to support family-school engagement in early childhood settings: Teacher and family perspectives. Early Child Development and Care, 190(4), 447-46o. https://doi.org/10.1080/03004430.2018.1479401

Swindle, T. M., Ward, W. L., \& Whiteside-Mansell, L. (2018). Facebook: The use of social media to engage parents in a preschool obesity prevention curriculum. Journal of Nutrition Education and Behavior, 50(1), 4-10. https://doi. org/10.1016/j.jneb.2017.05.344

Whaley, A. L., \& Longoria, R. A. (2009). Preparing card sort data for multidimensional scaling analysis in social psychological research: A methodological approach. The Journal of Social Psychology, 149(1), 105-115. https://doi.org/10.3200/SOCP.149.1.105-115

Willis, G. B. (2004). Cognitive interviewing: A tool for improving questionnaire design. Sage Publications. 